\title{
Strongyloidiasis in immigrants and refugees in Canada
}

\section{Courtney Thompson MD, Andrea K. Boggild MSc MD}

\section{Strongyloidiasis is a potentially life- threatening infection caused by the soil-transmitted helminth Strongy- loides stercoralis}

Strongyloides stercoralis is an intestinal roundworm transmitted primarily through barefoot skin exposure in the tropics or subtropics. Acute infection may present with papular rash, cough or wheezing, and gastrointestinal symptoms. ${ }^{1}$ Manifestations of chronic infection are present in up to half of infected patients and may include abdominal pain, diarrhea, vomiting, recurrent asthma, a Löffler-like syndrome, larva currens (Figure 1) or pruritis ani. Eosinophilia may be absent.

\section{Without treatment, strongyloidiasis is a lifelong infection}

Autoinfection is a unique feature of $S$. stercoralis enabling lifelong persistence, potentially for decades after immigration. ${ }^{1}$ Larvae passed in the stool are capable of re-infecting humans. ${ }^{1}$ Suspicion of chronic strongyloidiasis rests upon the epidemiologic history, as most patients are asymptomatic. Active screening and treatment of at-risk groups eradicates infection and eliminates the risk of future severe complications, including death. Persons at risk should be screened with serologic tests (enzyme immunoassay), which are highly sensitive. ${ }^{4}$ Though definitive for diagnosis, demonstration of parasites in stool is an insensitive test. Serologic testing is performed at reference laboratories, including the National Reference Centre for Parasitology in Montréal (www.medicine.mcgill.ca/tropmed/txt/ services.htm\#STRONGLYOIDIASIS).

\section{References}

1. Greaves D, Coggle S, Pollard C, et al. Strongyloides stercoralis infection. BMJ 2013;347: 44610

2. Schär F, Trostdorf U, Giardina F, et al. Strongy loides stercoralis: global distribution and risk

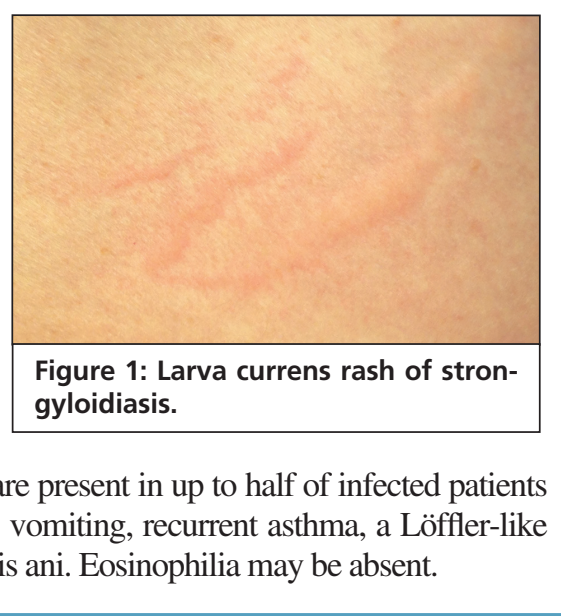

Disseminated strongyloidiasis is a complication with high mortality

Dissemination involves widespread migration of larvae to multiple organ systems. Bacteremia can result from gut translocation, as larvae exit the gut and migrate through tissue. ${ }^{1}$ The case-fatality rate is at least $68.5 \%(100 \%$ if untreated). ${ }^{5}$ Risk factors for dissemination include immunosuppression by oral glucocorticoids, human T-cell lymphotrophic virus type I infection, bone marrow or solid organ transplant, hypogammaglobulin-emia and malnutrition. Patients with a history of travel to or previous residence in an endemic country should be screened before initiation of any immunosuppression, including short courses of steroids.

factors. PLoS Negl Trop Dis 2013;7:e2288.

3. Pottie K, Greenaway C, Feightner J, et al. Evidencebased clinical guidelines for immigrants and refugees. CMAJ 2011;183:E824-925.

4. Bisoffi Z, Buonfrate D, Sequi M, et al. Diagnostic accuracy of five serologic tests for Strongyloides stercoralis infection. PLoS Negl Trop Dis 2014; 8:e2640.

5. Suputtamongkol Y, Premasathian N, Bhumimuang $\mathrm{K}$, et al. Efficacy and safety of single and double doses of ivermectin versus 7-day high dose albendazole for chronic strongyloidiasis. PLoS Negl Trop Dis 2011;5:e1044.
Screening for strongyloidiasis is recommended in Canada for refugees from Southeast Asia and Africa and is strongly suggested for immigrants from endemic countries

Global estimates of prevalence suggest that strongyloidiasis affects up to $40 \%$ of the population in the tropics and subtropics. ${ }^{2}$ It is estimated to affect $9 \%-77 \%$ of immigrants and refugees in Canada, with highest prevalence among those from Southeast Asia. ${ }^{3}$ Endemic regions include South America, Africa, Southeast Asia and the Caribbean.

In Canada, medication to treat strongyloidiasis is available only through the Special Access Programme of Health Canada

Ivermectin $(200 \mu \mathrm{g} / \mathrm{kg})$ given as a single dose and repeated two weeks later is the treatment of choice for simple intestinal strongyloidiasis, including asymptomatic infections, and is more than $95 \%$ effective. ${ }^{5}$ Management of strongyloidiasis, particularly disseminated disease, should be performed in consultation with an expert in migrant health or tropical infectious diseases.

Competing interests: Andrea Boggild is a member of the Committee to Advise on Tropical Medicine and Travel, an external advisory body to the Public Health Agency of Canada. No other competing interests were declared.

This article has been peer reviewed.

Affiliations: Department of Medicine (Thompson, Boggild), University of Toronto; Public Health Ontario Laboratories (Boggild), Public Health Ontario; Tropical Disease Unit (Boggild), Division of Infectious Diseases, Toronto General Hospital, University Health Network, Toronto, Ont.

Correspondence to: Andrea Boggild, andrea.boggild@utoronto.ca

CMAJ 2015. DOI:10.1503/cmaj.141441 